\title{
A Goal Programming Approach to Nurse Scheduling with Individual Preference Satisfaction
}

\author{
Pavinee Rerkjirattikal (D), 1,2 Van-Nam Huynh (D), Sun Olapiriyakul ${ }^{2}{ }^{1}$ \\ and Thepchai Supnithi $\mathbb{D B}^{3}$ \\ ${ }^{1}$ School of Manufacturing Systems and Mechanical Engineering, Sirindhorn International Institute of Technology, \\ Thammasat University, Pathum Thani 12120, Thailand \\ ${ }^{2}$ School of Knowledge Science, Japan Advanced Institute of Science and Technology, Nomi, Ishikawa 923-1211, Japan \\ ${ }^{3}$ Language and Semantic Research Team, National Electronics and Computer Technology Center, \\ Pathum Thani 12120, Thailand \\ Correspondence should be addressed to Sun Olapiriyakul; suno@siit.tu.ac.th
}

Received 18 June 2020; Revised 3 November 2020; Accepted 5 November 2020; Published 23 November 2020

Academic Editor: Danielle Costa Morais

Copyright (c) 2020 Pavinee Rerkjirattikal et al. This is an open access article distributed under the Creative Commons Attribution License, which permits unrestricted use, distribution, and reproduction in any medium, provided the original work is properly cited.

\begin{abstract}
The use of scheduling optimization tools is essential in creating an efficient nurse shift-rotation schedule. A well-designed nurse scheduling technique can improve nurses' job satisfaction and their intention to stay. This study develops a goal programming approach to nurse scheduling that simultaneously considers workload fairness and individual preferences on working shift and day off assignments. A case study of an operating room at a hospital in Thailand is used to illustrate the model capabilities for solving an actual nurse scheduling problem. The job satisfaction factors defined based on an interview and questionnaire survey are integrated into the model. When compared against the manual scheduling result, the optimal schedules can be implemented to improve the nurse's perception of fairness and preference satisfaction. The analysis of fairness and multiple individual preferences based on a case study investigation is the main contribution of this study.
\end{abstract}

\section{Introduction}

The problem of intensified workload and poor working conditions has been identified as one of the major causes of the global nurse shortage predicament [1]. Hospital nurses who do shift work are exposed to understaffing, heavyworkload, and irregular work-scheduling conditions. The overworking and understaffing of nursing staff not only adversely affect the service quality of healthcare operations, but also lead to less patient-nurse interaction [2] and patient safety issues (Liu et al. [3] and Baker et al. [4]). At the same time, the demanding working conditions also impose various negative health consequences on nurses including fatigue, obesity, sleep disorder, and a wide range of chronic diseases [5]. The impact of shift work also includes decreased work-life balance, which can significantly affect nurse's job satisfaction and retention intention [6].
The positive effects of job satisfaction on nurse retention have been addressed in many countries [7-10]. For any profession, the control of job satisfaction in the workplace is an indefinite task due to the variations in job characteristics and individual characteristics. The understanding of the impacts of both types of characteristics is crucial in improving job satisfaction [11]. According to the nurse job satisfaction literature, the work environment is an important job characteristic affecting nurse job satisfaction and retention intention. DeKeyser Ganz and Toren [12] reviews that a well-designed nurse practice environment that promotes nurse engagement in management, staffing adequacy, and positive relations among colleagues is essential for ensuring job satisfaction and preventing the intention to leave. A survey in the underserved areas of Jordan by AbuAlRub et al. [13] suggests that the design of a work environment that promotes job satisfaction and nurse 
intention to stay should consider the shortcomings of nurses' living conditions. Recent job satisfaction studies tend to include both job and individual characteristics in their investigation. The perceptions of job autonomy and organizational justice have received more research attention than other individual characteristics in recent literature. As shown in Li et al. [14], Giles et al. [15], Mahoney et al. [16], and Koning [17], the perception of job control or autonomy is an important job satisfaction factor that can improve job satisfaction and nurse retention. With autonomy, nurses take part in their shift scheduling process, enabling the direct consideration of their preferences. Organizational justice is another key factor affecting nurse job satisfaction [18]. The recent survey study by Rizany et al. [19] indicates that the implementation of nurse schedules developed by a systematic scheduling method with organizational justice consideration has a positive effect on nurse job satisfaction. The studying results suggest that organizational justice can be achieved by providing an equitable allocation of workload and favorable scheduling outcomes. In a shift-rotation system, many personal preferences can be considered including the preferred shift time, day off, coworkers, etc.

The development of nurse scheduling algorithms has received significant research attention to resolve the job satisfaction and retention issues that are becoming more problematic in different countries. The use of mathematical programming in nurse scheduling tasks helps not only reduce the burdensome and time-consuming manual scheduling efforts, but also allow any change to be made to the initial scheduling easily. Nurse scheduling problems (NSP) have been widely studied in the literature to date. The primary objective of nurse scheduling is to satisfy the hospital's patient demand and staffing policies. For jobsatisfaction-enhanced NSP, the fairness and nurse preferences are incorporated into the scheduling models in the form of constraints and objectives. When compared to manual scheduling, which is still widely used by hospitals, the job-satisfaction-enhanced models are capable of producing more fair schedules, as shown by the previous case studies $[20,21]$. The manual scheduling task allows schedulers to have the control to assign schedules based on their judgment and may result in an unfair schedule. Manual scheduling is also time-consuming, preventing the rescheduling of nurses shifts should any disruption occurs during the implementation of the proposed schedule. As a result, the original attempt to create a fair and job-satisfaction-enhanced schedule can be compromised. Both single- and multiple-objective techniques have been used in formulating job-satisfaction-enhanced NSP models. Schedulers can maximize or control the level of job satisfaction while being able to pursue other operating objectives. Thus far, there exists a research gap concerning the integration of workforce and individual preferences into nurse scheduling practices. There is also very limited research that combines fairness and preference goals in NSP and use an actual case study to illustrate the practicality of the proposed approach. The details of the literature review are given in the next section. After that, materials and methods are described to gain insights into how the proposed NSP model is developed based on the operating-room-nurse case study. Results and discussion are given to see how the scheduling solutions allocate nurses in response to the simultaneous consideration of multiple scheduling goals. In the end, the conclusion of findings and the main research contributions are provided.

\section{Literature Review}

The research of NSP has been well-documented in the previous studies for different designing and solving approaches. Especially during the past decade, there has been a growing NSP literature focusing on the job satisfaction of nurses. Many studies in the literature develop nurse scheduling approaches that create positive effects on job satisfaction based on nurse preference. El Adoly et al. [20] proposed a scheduling algorithm that considers shift and day off preferences and uses an actual hospital case study in Egypt for model validation. Thongsanit et al. [22] applied the nurse scheduling technique to balance shift assignments among the nurses. The aim is to improve overall nurse preferences in a hospital in Thailand. Similarly, Cetin and Sarucan [23] aimed for balancing the total work hours among the nurses. They consider factors influencing nurses' preferences such as the desirable shift patterns, weekend day off allocation, and balance between day and night shifts. However, these preferences are based on the group, not individual preferences. Another group of NSP studies makes it possible to specify individual nurse scheduling preferences on shift and day off. Deterministic (Lin et al. [24], Huang et al. [25], and Widyastiti et al. [26]) and stochastic (Bagheri et al. [27]) single-objective linear programming approaches are proposed. The exact or optimization techniques such as Linear programming (LP) or Mixed-integer programming (MIP) have shown to be effective in solving NSP. In more recent NSP studies, the development of fair and preference scheduling using multiobjective optimization techniques such as Goal programming (GP) is observed. The use of GP allows the planners to regard job satisfaction factors as optimization goals. Then, the relative importance of each goal can be assigned to reach the most suitable scheduling solutions. Lim et al. [28] proposed a goal programmingbased NSP considering assignment cost, idle time, and nurse preferences simultaneously. In Agyei et al. [29] and Al-Hinai et al. [30] studies, goal programming is used to generate balanced shift assignments for nurses. The undesirable shift patterns or shift precedence is regarded as the main job satisfaction factors. The use of goal programming to reach multi-criteria scheduling decisions is also found in Dumrongsiri and Chongphaisal [31]. The desirable shift work characteristics for an emergency room with nurses' skill heterogeneity in a Thai university hospital are formulated as the GP objectives. Mohammadian et al. [32]'s proposed a GP model to solve an NSP using an emergency room in a hospital in Tehran as a case study. In their case, nurses are entirely homogeneous in skill and experience levels. Their highlight is the formation of seven goals related to the desirable shift work characteristics and nurses' interests. Aside from the skill consideration, these two multi-criteria 
scheduling approaches aim to maximize job satisfaction based on a different set of hard and soft constraints.

Based on this part of the literature, GP allows decisionmakers to find practical solutions based on the desirable scheduling characteristics with target values. The problemsolving is executed by minimizing the unwanted deviation from the target values. At this point, the goals' priority level can be defined based on management interests. Wang et al. [21] developed a weighted goal programming NSP by assigning the overtime restriction as the most important goal. Sundari and Mardiyati [33] formulated a preemptive goal programming NSP, where the goals related to hospital regulations are to be satisfied before nurses' preferences. Another interesting area of NSP literature is the formulating and solving of highly constraint NSP. In this case, previous studies such as Santos et al. [34], Mischek and Musliu [35], and Rahimian et al. [36] use constraint programming (CP) to find feasible solutions rather than optimal solutions based on hard and soft constraints. Hard constraints include hospital regulations and restrictions that need to be satisfied. Soft constraints are those that are formulated based on personal preferences, which can be violated at a penalty.

In the NSP literature, heuristic algorithms are important tools researchers use to solve large-scale NSP. Chiaramonte and Caswell [37] proposed an advanced nurse scheduling algorithm named as competitive nurse rostering and rerostering. The algorithm offers a rerostering ability to generate alternate cost-optimal scheduling solutions that have a minimum negative impact on nurse preferences. An iterated local search is proposed as the solving tool. Zhong et al. [38] develop a two-stage heuristic algorithm to create a nurse schedule with a balanced weekend workload. The algorithm accounts for the individual nurse preferences, patient volume fluctuation, required patient-to-nurse ratio, and other work-rest rules. The solution impact of uncertainty arising from the patient volume fluctuation is shown to be significant for the US hospital case study. The investigation of uncertain impacts is important and has been the subject of an investigation by several other NSP studies. The study of Maass et al. [39] accounts for not only uncertainty arising from patient demand, but also nurse absenteeism. Their model is solved by using the genetic algorithm (GA) to create long-term staffing decisions for different tiers of nursing staff. Leksakul and Phetsawat [40] also use GA to solve NSP that considers the demand for nurse and fair overtime pay for nurses. In Sajadi et al. [41], simulated annealing (SA) and simulation are used in tandem in searching for solutions with less patient wait time. In their NSP, the simulation of emergency room activities in a hospital case study is performed, considering important input data such as patient arrival rate and nurse service time. In the model of Liu et al. [42], the wage of nurses and preference penalty costs are combined into a single cost minimization objective. The computational performances of their proposed heuristic approach are benchmarked against those of several meta-heuristics approaches. Guessoum et al. [43] proposed a two-stage method where the original NSP is reduced in size by a variable fixing heuristic and solvable to optimal or near-optimal by an exact method.
In the current satisfaction-enhanced NSP research pool, the existing models are dedicated to maximizing nurse preferences, desirable scheduling characteristics, and satisfaction. However, there is still a need for more case study research to accommodate the constant change of the NSP context. For nurse scheduling, the exploration of the practicality of the proposed approach based on an actual case study is also important [44]. Regarding job satisfaction factors, there are still limited studies that consider individual preferences together with fairness. This research aims to strengthen the fundamental understanding of the actual nurse scheduling case and to develop a fair and satisfactionenhanced scheduling tool that can be implemented easily on-site by the existing personnel. Our first step is to conduct field surveys at an operating room department in a private hospital located in Pathum Thani, Thailand. The survey objective is to define the system parameters based on the actual job satisfaction factors, scheduling regulations, and problem environment. The second step is to formulate a mathematical scheduling model, using GP, to achieve all the scheduling goals concerning fairness and job satisfaction. A free add-in optimization software in Microsoft Excel called Opensolver is used, so that it can be implemented by the head nurse without any additional cost or complication.

\section{Materials and Methods}

3.1. Case Study and Data Collection. This research focuses on the scheduling of operating-room nurses in a private hospital with 200 beds in Pathum Thani, Thailand. A field survey, an interview with the head nurse, and a questionnaire survey with operating room nurses were conducted during December-January 2019/20. The operating room has 17 nurses (1 head nurse and 16 full-time nurses), working in a 3-shift rotation system: morning shift (8:00-16:00), afternoon shift (16:00-24:00), and night shift (0:00-8:00). Currently, the shift schedule is manually generated by the head nurse at the beginning of each month. In the case presented, the scheduling period of 28 days is assumed. The main scheduling task is to assign an adequate number of nurses for each shift across the scheduling period. The scheduling criteria and the relevant hospital's regulations are given in the next section. Aside from these scheduling requirements, based on the survey and interview results, the fairness of workload and job satisfaction of nurses are the areas of interest for management and of this research. The questionnaire survey results indicate that shift and day off preferences are the important parameters contributing to nurses' job satisfaction, mainly because operation room tasks are nonrepetitive and require a variety of skills. However, for the case where nurses are required to perform repetitive tasks over an extended period, job satisfaction factors related to fatigue and job boredom may need to be considered. The job satisfaction effects of job boredom in workforce scheduling research have been investigated in our recent study [45].

To improve job satisfaction, this study develops a nurse scheduling approach that improves nurse's perception of workload fairness and preference fulfillment. A 
questionnaire is administered to nurses asking them to indicate their preferred shifts and days off across the 28-day scheduling period. Each nurse specifies 8 preferred days off: 4 most preferred days off and 4 second-most preferred days off. A goal programming model for nurse scheduling is formulated to simultaneously address a set of multiple jobsatisfaction enhancement objectives: (1) minimizing the unbalanced workload, (2) minimizing the unbalanced preferred shift, and (3) minimizing the unbalanced preferred day off among the nurses. The details of model formulation are as follows.

3.2. Mathematical Model Formulation. The proposed nurse scheduling model is formulated for multishift scheduling over a series of consecutive sequences of days. The heterogeneous characteristics of nurses considered in the model include the experience levels and their preferences on shift and day off. The scheduling model is formulated to account for the shift time and the following case study's conditions and assumptions, which are similar in principle to the previous case study oriented NSP studies (Dumrongsiri and Chongphaisal [31], and Mohammadian et al. [32]).

\subsection{Modeling Conditions and Assumptions}

(i) The scheduling period is 28 days. In a workday, there are three 8-hour shifts: morning, afternoon, and night shifts.

(ii) The number of nurses in each shift must meet the requirements: 6 for the morning shift, 6 for the afternoon shift, and 2 for the night shift.

(iii) Based on the working experiences, nurses with working experience more and less than 5 years of experience are classified as level-1 and level-2 nurses, respectively.

(iv) In each shift, the number of level-1 (experienced) nurses must be at least half of the total number of nurses.

(v) Nurses must work no less than 22 shifts and no more than 24 shifts in a month.

(vi) Nurses must have at least one day off each week.

(vii) Nurses can work only one shift per day.

(viii) No more than 2 night shifts per week are allowed for each nurse.

(ix) Consecutive night shifts are not allowed.

(x) The head nurse always works on the morning shift from Monday to Saturday and takes a day off on Sunday.

(xi) Indices.

$i$ : number of nurses $(i=1, \ldots, I)$

$j$ : number of shifts $(j=1, \ldots, J ; M=$ morning, $\mathrm{A}=$ afternoon, $\mathrm{N}=$ night $)$

$k$ : number of days in the planning horizon $(k=1$, $\ldots, K)$

(xii) Input parameters.
$R_{j}$ : number of required nurses in each shift $j$.

$E_{i}$ : level- $i$ nurse (level 1 is an experienced nurse).

$P S_{i, j, k}$ : nurses preferences on working shifts and workdays ( $=1$ if nurse $i$ prefers to work in shift $j$ on day $t)$.

$P D_{i, k}$ : nurses preferences score on days off ( $=1$ if day $k$ is nurse's $i$ second-most preferred day off, $=3$ if day $k$ is nurse's $i$ most preferred day off). $W S_{\text {Min }}:$ minimum monthly working shifts allowed.

$W S_{\text {Max }}$ : maximum monthly working shifts allowed.

$S_{\text {Target }}$ the target number of working shifts.

$P S_{\text {Target }}$ : yhe target number of preferred shift.

$P D_{\text {Target }}$ : the target preferred day off scores.

(xiii) Decision variables.

$X_{i, j, k}=1$ if nurse $i$ is assigned to work in shift $j$ on day $k, 0$ otherwise.

$Y_{i, k}=1$ if nurse $i$ is assigned to take a day off on day $k, 0$ otherwise.

$S_{i}^{+}, S_{i}^{-}$: positive and negative deviation of the number of shifts from the target for nurse $i$.

$P S_{i}^{+}, P S_{i}^{-}$: positive and negative deviation of the number of preferred shifts from the target for nurse $i$.

$P D_{i}^{+}, P D_{i}^{-}$: positive and negative deviation of the preferred day off scores from the target for nurse $i$.

The proposed nurse scheduling model is formulated using the normalized goal programming technique, as shown below. The first goal equation is formulated to balance the number of shifts assigned to nurses. The second and third goal equations aim to consider the individual preferences on shift and day off, respectively, enabling the improvement of autonomy of nurses over their work schedule.

Goal 1. The number of overworked or underworked shifts of each nurse is determined based on the total number of shifts assigned and the target number of working shifts, as shown in equation (1). Both overworking and underworking are regarded as an undesirable scheduling outcome.

$$
\sum_{j=1}^{J} \sum_{k=1}^{K} X_{i, j, k}-S_{i}^{+}+S_{i}^{-}=S_{\text {Target }}, \quad \forall i .
$$

Goal 2. The numbers of preferred and nonpreferred shifts assigned to each nurse are calculated using equation (2). The undesirable scheduling outcome occurs when the number of nonpreferred shifts exceeds the target value.

$$
\left(\sum_{j=1}^{J} \sum_{k=1}^{K} P S_{i, j, k} \cdot X_{i, j, k}\right)-P S_{i}^{+}+P S_{i}^{-}=P S_{\text {Target }}, \quad \forall i .
$$

Goal 3. The number of preferred days off assigned is determined using equation (3). The undesirable scheduling outcome occurs when the score of nonpreferred days off is lower than the target value. 


$$
\left(\sum_{k=1}^{K} P D_{i, k} \cdot Y_{i, k}\right)-P D_{i}^{+}+P D_{i}^{-}=P D_{\text {Target }}, \quad \forall i
$$

The scheduling objective is to simultaneously minimize the undesirable scheduling outcomes related to the three goals. The undesirable outcome of each goal is normalized to its target value. The objective function defined in equation (4) is to minimize the summation of normalized undesirable outcomes as shown below.

$$
\begin{aligned}
& \operatorname{minimize} Z=\left(\frac{\sum_{i=1}^{I}\left(S_{i}^{+}+S_{i}^{-}\right)}{S_{\text {Target }} \cdot I}\right)+\left(\frac{\sum_{i=1}^{I}\left(P S_{i}^{-}\right)}{P S_{\text {Target }} \cdot I}\right) \\
& +\left(\frac{\sum_{i=1}^{I}\left(P D_{i}^{-}\right)}{P D_{\text {Target }} \cdot I}\right) \\
& \text { subject to } \sum_{i=1}^{I} X_{i, j, k}=R_{j}, \quad \forall j, k \\
& W S_{\text {Min }} \leq \sum_{j=1}^{J} \sum_{k=1}^{K} X_{i, j, k} \leq W S_{\text {Max }}, \quad \forall i \\
& X_{i, j, k}+X_{i, j+1, k}+X_{i, j+2} \leq 1, \quad \forall i, j, k \\
& \sum_{i=1}^{I} E_{i} \cdot X_{i, j, k} \geq 0.5 \cdot R_{j}, \quad \forall j, k, E_{i}=1 \\
& \sum_{j=1}^{J} X_{i, j, k}+Y_{i, k}=1, \quad \forall i, k \\
& \sum_{j=N} \sum_{k=1}^{K} X_{i, j, k} \leq 2, \quad \forall i \\
& \sum_{j=N} \sum_{k=k}^{k+1} X_{i, j, k} \leq 1, \quad \forall i \\
& \sum_{i=k}^{k+6} Y_{i, k} \geq 1, \quad \forall i, k \in 1,8,15,21 \\
& X_{i=\text { Head nurse }, j=M, k}=1, \quad \forall k \\
& X_{i=\text { Head nurse }, k=\text { Sunday }}=1 \\
& S_{i}^{+}, S_{i}^{-}, P S_{i}^{+}, P S_{i}^{-}, P D_{i}^{+}, P D_{i}^{-} \in Z^{+}, \quad \forall i .
\end{aligned}
$$

Equation (5) ensures that the number of nurses assigned to each shift meets the requirements. Equation (6) limits the minimum and the maximum number of working shifts per month for nurses. Equation (7) allows nurses to work only one shift per day. Equation (8) ensures an adequate number of experienced nurses in each shift. Equation (9) ensures that there is no shift assignment on a day off. Equation (10) makes certain that the allowable number of night shifts per week is enforced. Equation (11) prohibits the consecutive night shift assignment. Equation (12) ensures that each nurse is entitled to at least one day off per week. Equations (13) and (14) account for the head nurse's fixed schedule. Equation (15) defines deviation variables to be positive integers.

3.4. Case Study Data. The model is validated using the collected case study data. The minimum and the maximum number of shifts per month are 22 and 24, respectively. According to the head nurse, the targets related to the 3 goals are given in Table 1.

The nurses are asked to identify their preferred shifts throughout the planning period of 28 days. The first 14 days of shift preference data are shown in Table 2. For the day off preference, nurse preference data are obtained by using Likert scales rather than binary response scales used by the previous studies [31, 32]. In our questionnaire survey, the nurses are asked to rate how each shift and day off fits their scheduling needs. The ratings provide more scheduling flexibility and a higher chance of maximizing the satisfaction of all nurses. In our case, the most and second-most preferred days off worth 3 and 1 points, respectively. The target preferred day off score $\left(P D_{\text {Target }}\right)$ of 12 is achieved when the most preferred day off is assigned as the actual day off of every week throughout the 28-day planning period. The first 14 days of the day off preference sheets are shown in Table 3.

\section{Results and Discussion}

In this part, the problem is divided into three scenarios: normal operation, extended capacity operation, and higher demand for experienced nurses. The number of nurses required for the normal operation over the three shifts is 6,6 , and 2 . For the extended capacity operation, the number of nurses required is 9,6 , and 2 . It is assumed that the morningshift capacity is extended to handle high patient demand in the morning. It is worth noting that the scheduling requirements such as the number of shifts allowed and the unallowable shift patterns are formulated as hard constraints in this study. Such model formulation does not provide enough flexibility to conduct an extensive sensitivity analysis. If these hard constraints are reformulated as goal equations and soft constraints, a sensitivity analysis can be performed in a broader sense by varying the design parameters such as the number of nurses available. Here, only the normal and extended capacity scenarios are analyzed.

4.1. Normal Operation Scenario. The goal-programming nurse scheduling model is solved using Opensolver version 2.9.0. The case study problem can be solved to optimality within 5 seconds, using a $2.3 \mathrm{GHz}$ Dual-Core Intel Core i5$8300 \mathrm{H}$ operating system. In Table 4 , the total numbers of shifts, preferred shifts, and preferred days off assigned to 17 nurses over 28 days are summarized. The actual total number of shifts assigned to nurses based on the schedule that was manually produced in the month before the data collection period is also shown. The details of the optimal 
TABLE 1: The goal targets.

Target number of working shifts $\left(S_{\text {Target }}\right)$

24 shifts

Target number of preferred shifts $\left(P S_{\text {Target }}\right)$

20 shifts

Target preferred day off score $\left(P D_{\text {Target }}\right)$

12 points

TABle 2: Nurses' preferred working shifts.

\begin{tabular}{|c|c|c|c|c|c|c|c|c|c|c|c|c|c|c|c|}
\hline Nurse & EXP & $D 1$ & D2 & D3 & $D 4$ & D5 & D6 & D7 & $D 8$ & $D 9$ & $D 10$ & $D 11$ & $D 12$ & $D 13$ & $D 14$ \\
\hline 1 & $1(\mathrm{H})$ & $\mathrm{M}$ & $\mathrm{M}$ & $\mathrm{M}$ & $\mathrm{M}$ & $\mathrm{M}$ & $\mathrm{M}$ & $\mathrm{M}$ & $\mathrm{M}$ & $\mathrm{M}$ & $\mathrm{M}$ & $M$ & $\mathrm{M}$ & $\mathrm{M}$ & $\mathrm{M}$ \\
\hline 2 & 1 & $\mathrm{M}$ & A & A & A & $\mathrm{M}$ & $\mathrm{M}$ & $\mathrm{M}$ & A & A & A & $\mathrm{N}$ & A & A & A \\
\hline 3 & 1 & $\mathrm{M}$ & $\mathrm{M}$ & $\mathrm{M}$ & $\mathrm{M}$ & $\mathrm{M}$ & $\mathrm{N}$ & $\mathrm{M}$ & $\mathrm{M}$ & $\mathrm{M}$ & $\mathrm{M}$ & $\mathrm{M}$ & $\mathrm{M}$ & $\mathrm{M}$ & A \\
\hline 4 & 1 & $\mathrm{~A}$ & $\mathrm{~A}$ & A & $\mathrm{A}$ & A & $\mathrm{M}$ & A & A & A & A & $\mathrm{M}$ & $\mathrm{N}$ & $\mathrm{M}$ & $\mathrm{M}$ \\
\hline 5 & 1 & $\mathrm{M}$ & $\mathrm{M}$ & $\mathrm{A}$ & $\mathrm{A}$ & $\mathrm{A}$ & $\mathrm{A}$ & $\mathrm{N}$ & $\mathrm{A}$ & $\mathrm{A}$ & A & A & A & $\mathrm{M}$ & $\mathrm{M}$ \\
\hline 6 & 1 & A & $\mathrm{A}$ & A & $\mathrm{A}$ & A & $\mathrm{N}$ & A & A & A & A & A & $\mathrm{M}$ & M & $\mathrm{M}$ \\
\hline 7 & 1 & $\mathrm{M}$ & $\mathrm{M}$ & $\mathrm{M}$ & $\mathrm{M}$ & $\mathrm{M}$ & A & $\mathrm{A}$ & A & $\mathrm{A}$ & A & A & A & $\mathrm{N}$ & A \\
\hline 8 & 1 & $\mathrm{~A}$ & $\mathrm{~A}$ & A & $\mathrm{A}$ & $\mathrm{A}$ & $\mathrm{A}$ & $\mathrm{M}$ & $\mathrm{M}$ & $\mathrm{M}$ & $\mathrm{M}$ & $\mathrm{M}$ & $\mathrm{M}$ & $\mathrm{M}$ & $\mathrm{M}$ \\
\hline 9 & 1 & $\mathrm{~A}$ & $\mathrm{~A}$ & $\mathrm{M}$ & $\mathrm{M}$ & $\mathrm{M}$ & $\mathrm{M}$ & A & A & A & A & $\mathrm{N}$ & A & A & $\mathrm{N}$ \\
\hline 10 & 2 & $\mathrm{M}$ & $\mathrm{M}$ & $\mathrm{M}$ & $\mathrm{M}$ & $\mathrm{M}$ & $\mathrm{M}$ & $\mathrm{M}$ & $\mathrm{M}$ & $\mathrm{M}$ & $\mathrm{M}$ & $\mathrm{M}$ & $\mathrm{M}$ & $\mathrm{M}$ & $\mathrm{M}$ \\
\hline 11 & 2 & A & A & A & $\mathrm{A}$ & $\mathrm{A}$ & $\mathrm{N}$ & A & A & A & $\mathrm{N}$ & $\mathrm{M}$ & $\mathrm{M}$ & $\mathrm{M}$ & $\mathrm{M}$ \\
\hline 12 & 2 & $\mathrm{M}$ & $\mathrm{M}$ & A & $\mathrm{A}$ & A & $\mathrm{M}$ & $\mathrm{M}$ & $\mathrm{M}$ & $\mathrm{M}$ & $\mathrm{M}$ & $\mathrm{N}$ & A & A & A \\
\hline 13 & 2 & $\mathrm{M}$ & $\mathrm{M}$ & $\mathrm{M}$ & $\mathrm{M}$ & $\mathrm{M}$ & $\mathrm{A}$ & A & A & A & A & $\mathrm{N}$ & A & A & A \\
\hline 14 & 2 & A & A & $\mathrm{A}$ & A & A & A & A & $\mathrm{M}$ & $\mathrm{M}$ & $\mathrm{M}$ & $\mathrm{M}$ & $\mathrm{M}$ & $\mathrm{M}$ & $\mathrm{M}$ \\
\hline 15 & 2 & A & A & A & $\mathrm{N}$ & $\mathrm{A}$ & $\mathrm{M}$ & $\mathrm{M}$ & $\mathrm{M}$ & $\mathrm{M}$ & $\mathrm{M}$ & $\mathrm{M}$ & $\mathrm{A}$ & A & A \\
\hline 16 & 2 & $\mathrm{M}$ & $\mathrm{M}$ & $\mathrm{M}$ & $\mathrm{M}$ & $\mathrm{M}$ & A & $\mathrm{A}$ & A & A & A & A & A & $\mathrm{N}$ & A \\
\hline 17 & 2 & $\mathrm{~N}$ & $\mathrm{~A}$ & A & A & $\mathrm{A}$ & $\mathrm{M}$ & $\mathrm{M}$ & A & $\mathrm{A}$ & A & A & $\mathrm{N}$ & $\mathrm{A}$ & A \\
\hline
\end{tabular}

$\mathrm{EXP}=$ experience level, $\mathrm{H}=$ head nurse, $\mathrm{M}=$ morning shift, $\mathrm{A}=$ afternoon shift, $\mathrm{N}=$ night shift.

TABLE 3: Nurses' preferred day off.

\begin{tabular}{lccccccccccccccc}
\hline Nurse & EXP & $D 1$ & $D 2$ & $D 3$ & $D 4$ & $D 5$ & $D 6$ & $D 7$ & $D 8$ & $D 9$ & $D 10$ & $D 11$ & $D 12$ & $D 13$ & $D 14$ \\
\hline 1 & $1(\mathrm{H})$ & - & 1 & - & - & - & - & 3 & - & 1 & - & - & - & - & 3 \\
2 & 1 & - & - & 3 & - & - & 1 & - & - & 1 & - & - & 3 & - & - \\
3 & 1 & 1 & - & - & - & 3 & - & - & - & 3 & - & - & - & 1 & - \\
4 & 1 & - & 1 & - & - & - & - & 3 & 3 & - & - & 1 & - & - & - \\
5 & 1 & - & - & - & - & - & 3 & 1 & - & 1 & - & - & - & 3 & - \\
6 & 1 & - & - & - & 3 & - & 1 & - & - & - & 1 & 3 & - & - & - \\
7 & 1 & - & 3 & - & - & 1 & - & - & - & 1 & - & - & - & - & 3 \\
8 & 1 & 1 & - & - & - & - & 3 & - & 1 & - & - & - & 3 & - & - \\
9 & 1 & - & 1 & - & - & - & - & 3 & - & 3 & - & - & - & - & 1 \\
10 & 2 & - & 1 & - & - & 3 & - & - & - & - & 1 & - & 3 & - & - \\
11 & 2 & - & - & 1 & - & - & - & 3 & - & - & - & 1 & - & - & 3 \\
12 & 2 & 3 & - & - & - & - & - & 1 & - & - & 3 & - & - & 1 & - \\
13 & 2 & 3 & - & - & 1 & - & - & - & - & 3 & - & - & 1 & - & - \\
14 & 2 & - & 3 & - & - & - & 1 & - & 1 & - & - & - & - & 3 & - \\
15 & 2 & 1 & - & - & - & 3 & - & - & - & 1 & - & - & - & - & 3 \\
16 & 2 & - & - & 1 & - & - & 3 & - & - & - & 1 & - & 3 & - & - \\
17 & 2 & 3 & - & - & - & - & 1 & - & 3 & - & - & - & 1 & - & - \\
\hline
\end{tabular}

schedule concerning the deviation from the three goals are also given in the table.

The results mainly suggest that all the scheduling goals can be successfully achieved by using the proposed approach. Concerning the first goal, there are 4 nurses with zero deviation from the workload target of 24 shifts. The deviations from the workload target for all nurses are no more than 2 shifts. The workload among the nurses is reasonably balanced. Regarding the other two goals, the deviations from the target number of preferred shifts and target day off scores are insignificant. However, there is one nurse (nurse 2) who is subject to moderate levels of percent deviation across the three goals, compared to other nurses.
This scenario of one or a few people receiving not-too-good scheduling results to maximize the job satisfaction of the entire workforce may occur. This nurse needs to be compensated by a rise in the number of preferred shifts and day off assignments during the next scheduling period. At any rate, for these current optimal solutions, it is reasonable to conclude that all the goals are simultaneously satisfied.

4.2. Extended Capacity Operation Scenario. Based on the results of the extended capacity scenario, the number of nurses required increases from 17 to 20 to cope with the higher patient demand during the morning shift. The results 
TABLE 4: Summary of deviations from the goals of the NSP model for the normal scenario.

\begin{tabular}{|c|c|c|c|c|c|c|c|c|c|c|c|c|c|}
\hline \multirow[b]{2}{*}{ Nurse $i$} & \multirow{2}{*}{$\begin{array}{l}\text { Actual total } \\
\text { shifts }\end{array}$} & \multicolumn{4}{|c|}{ G1: working shifts balancing } & \multicolumn{4}{|c|}{ G2: preferred shift assignments } & \multicolumn{4}{|c|}{ G3: score of preferred day off assignments } \\
\hline & & $\begin{array}{l}\text { Total } \\
\text { shifts }\end{array}$ & $S_{i}^{-}$ & $\begin{array}{c}S \\
\text { Target } \\
\end{array}$ & $\begin{array}{c}\% \\
\text { Dev }^{*}\end{array}$ & $\begin{array}{c}\text { Total preferred } \\
\text { shifts }\end{array}$ & $\mathrm{PS}_{\mathrm{i}}^{-}$ & $\begin{array}{c}\text { PS } \\
\text { Target } \\
\end{array}$ & $\begin{array}{c}\% \\
\text { Dev* }^{*}\end{array}$ & $\begin{array}{c}\text { Total preferred day } \\
\text { off scores }\end{array}$ & $P D_{i}^{-}$ & $\begin{array}{c}P d \\
\text { Target } \\
\end{array}$ & $\begin{array}{c}\% \\
\text { Dev }^{*}\end{array}$ \\
\hline 1 & 24 & 23 & 1 & 24 & 0.3 & 20 & 0 & 20 & 4.3 & 12 & 0 & 12 & 5.7 \\
\hline 2 & 20 & 24 & 0 & 24 & 4.1 & 17 & 3 & 20 & 11.3 & 10 & 2 & 12 & 11.9 \\
\hline 3 & 20 & 23 & 1 & 24 & 0.3 & 18 & 2 & 20 & 6.1 & 11 & 1 & 12 & 3.1 \\
\hline 4 & 20 & 23 & 1 & 24 & 0.3 & 16 & 4 & 20 & 16.6 & 11 & 1 & 12 & 3.1 \\
\hline 5 & 24 & 22 & 2 & 24 & 4.6 & 18 & 2 & 20 & 6.1 & 11 & 1 & 12 & 3.1 \\
\hline 6 & 23 & 23 & 1 & 24 & 0.3 & 20 & 0 & 20 & 4.3 & 11 & 1 & 12 & 3.1 \\
\hline 7 & 21 & 23 & 1 & 24 & 0.3 & 18 & 2 & 20 & 6.1 & 11 & 1 & 12 & 3.1 \\
\hline 8 & 22 & 23 & 1 & 24 & 0.3 & 20 & 0 & 20 & 4.3 & 11 & 1 & 12 & 3.1 \\
\hline 9 & 24 & 24 & 0 & 24 & 4.1 & 20 & 0 & 20 & 4.3 & 12 & 0 & 12 & 5.7 \\
\hline 10 & 20 & 24 & 0 & 24 & 4.1 & 20 & 0 & 20 & 4.3 & 12 & 0 & 12 & 5.7 \\
\hline 11 & 20 & 22 & 2 & 24 & 4.6 & 20 & 0 & 20 & 4.3 & 12 & 0 & 12 & 5.7 \\
\hline 12 & 24 & 23 & 1 & 24 & 0.3 & 19 & 1 & 20 & 0.9 & 10 & 2 & 12 & 11.9 \\
\hline 13 & 20 & 23 & 1 & 24 & 0.3 & 20 & 0 & 20 & 4.3 & 12 & 0 & 12 & 5.7 \\
\hline 14 & 20 & 23 & 1 & 24 & 0.3 & 20 & 0 & 20 & 4.3 & 12 & 0 & 12 & 5.7 \\
\hline 15 & 24 & 24 & 0 & 24 & 4.1 & 20 & 0 & 20 & 4.3 & 12 & 0 & 12 & 5.7 \\
\hline 16 & 24 & 22 & 2 & 24 & 4.6 & 20 & 0 & 20 & 4.3 & 12 & 0 & 12 & 5.7 \\
\hline 17 & 24 & 23 & 1 & 24 & 0.3 & 20 & 0 & 20 & 4.3 & 11 & 1 & 12 & 3.1 \\
\hline Average & & & & & 1.9 & & & & 5.6 & & & & 5.4 \\
\hline
\end{tabular}

${ }^{*}$ Dev $=$ percent deviation from the average values.

TABLE 5: Summary of deviations from the goals of the NSP model for the extend capacity scenario.

\begin{tabular}{|c|c|c|c|c|c|c|c|c|c|c|c|c|c|}
\hline \multirow[b]{2}{*}{ Nurse $i$} & \multirow{2}{*}{$\begin{array}{l}\text { Actual total } \\
\text { shifts }\end{array}$} & \multicolumn{4}{|c|}{ G1: working shifts balancing } & \multicolumn{4}{|c|}{ G2: preferred shift assignments } & \multicolumn{4}{|c|}{ G3: score of preferred day off assignments } \\
\hline & & $\begin{array}{l}\text { Total } \\
\text { shifts }\end{array}$ & $S_{i}^{-}$ & $\begin{array}{c}S \\
\text { Target }\end{array}$ & $\begin{array}{c}\% \\
\text { Dev* }^{*}\end{array}$ & $\begin{array}{c}\text { Total preferred } \\
\text { shifts }\end{array}$ & $P S_{i}^{-}$ & $\begin{array}{c}\text { PS } \\
\text { Target }\end{array}$ & $\begin{array}{c}\% \\
\text { Dev* }^{*}\end{array}$ & $\begin{array}{c}\text { Total preferred day } \\
\text { off scores }\end{array}$ & $P D_{i}^{-}$ & $\begin{array}{c}P D \\
\text { Target }\end{array}$ & $\begin{array}{c}\% \\
\text { Dev }^{*}\end{array}$ \\
\hline 1 & 24 & 24 & 0 & 24 & 0.8 & 20 & 0 & 20 & 1.3 & 12 & 0 & 12 & 7.6 \\
\hline 2 & 20 & 24 & 0 & 24 & 0.8 & 16 & 4 & 20 & 19.0 & 10 & 2 & 12 & 10.3 \\
\hline 3 & 20 & 24 & 0 & 24 & 0.8 & 20 & 0 & 20 & 1.3 & 12 & 0 & 12 & 7.6 \\
\hline 4 & 20 & 23 & 1 & 24 & 3.4 & 20 & 0 & 20 & 1.3 & 10 & 2 & 12 & 10.3 \\
\hline 5 & 24 & 24 & 0 & 24 & 0.8 & 20 & 0 & 20 & 1.3 & 10 & 2 & 12 & 10.3 \\
\hline 6 & 23 & 24 & 0 & 24 & 0.8 & 20 & 0 & 20 & 1.3 & 12 & 0 & 12 & 7.6 \\
\hline 7 & 21 & 24 & 0 & 24 & 0.8 & 20 & 0 & 20 & 1.3 & 9 & 3 & 12 & 19.3 \\
\hline 8 & 22 & 24 & 0 & 24 & 0.8 & 20 & 0 & 20 & 1.3 & 12 & 0 & 12 & 7.6 \\
\hline 9 & 24 & 24 & 0 & 24 & 0.8 & 19 & 1 & 20 & 3.8 & 9 & 3 & 12 & 19.3 \\
\hline 10 & 20 & 24 & 0 & 24 & 0.8 & 20 & 0 & 20 & 1.3 & 10 & 2 & 12 & 10.3 \\
\hline 11 & 20 & 23 & 1 & 24 & 3.4 & 20 & 0 & 20 & 1.3 & 11 & 1 & 12 & 1.3 \\
\hline 12 & 24 & 24 & 0 & 24 & 0.8 & 20 & 0 & 20 & 1.3 & 12 & 0 & 12 & 7.6 \\
\hline 13 & 20 & 24 & 0 & 24 & 0.8 & 20 & 0 & 20 & 1.3 & 12 & 0 & 12 & 7.6 \\
\hline 14 & 20 & 23 & 1 & 24 & 3.4 & 20 & 0 & 20 & 1.3 & 11 & 1 & 12 & 1.3 \\
\hline 15 & 24 & 24 & 0 & 24 & 0.8 & 20 & 0 & 20 & 1.3 & 12 & 0 & 12 & 7.6 \\
\hline 16 & 24 & 23 & 1 & 24 & 3.4 & 20 & 0 & 20 & 1.3 & 11 & 1 & 12 & 1.3 \\
\hline 17 & 24 & 24 & 0 & 24 & 0.8 & 20 & 0 & 20 & 1.3 & 12 & 0 & 12 & 7.6 \\
\hline 18 & - & 24 & 0 & 24 & 0.8 & 20 & 0 & 20 & 1.3 & 12 & 0 & 12 & 7.6 \\
\hline 19 & - & 24 & 0 & 24 & 0.8 & 20 & 0 & 20 & 1.3 & 12 & 0 & 12 & 7.6 \\
\hline 20 & - & 24 & 0 & 24 & 0.8 & 20 & 0 & 20 & 1.3 & 12 & 0 & 12 & 7.6 \\
\hline Average & & & & & 1.3 & & & & 2.3 & & & & 8.4 \\
\hline
\end{tabular}

${ }^{*}$ Dev $=$ percent deviation from the average value.

are summarized in Table 5. The working shift balance objective is well achieved. The shift and day off assignments are also quite consistent with the nurse preferences. In the optimal solution, there is only one nurse whose preferredshift deviation is up to 4 . Other nurses' shift preferences are well satisfied. With the increased number of nurses, it may be easier to proportionately distribute the workload. Solving this problem scenario consumes only 5 seconds. The computational performance of the proposed scheduling approach is also tested using larger problem sizes. It is found that the optimal solution with 50 nurses can be achieved within 20 seconds.

4.3. Higher Demand for Experienced Nurses Scenario. This scenario is created under the assumption that more experienced nurses are required on Monday and Tuesday mornings due to the need to cope with a large number of 
TABLE 6: Summary of deviations from the goals of the NSP model for the scenario with busy days.

\begin{tabular}{|c|c|c|c|c|c|c|c|c|c|c|c|c|c|}
\hline \multirow[b]{2}{*}{ Nurse $i$} & \multirow{2}{*}{$\begin{array}{l}\text { Actual total } \\
\text { shifts }\end{array}$} & \multicolumn{4}{|c|}{ G1: working shifts balancing } & \multicolumn{4}{|c|}{ G2: preferred shift assignments } & \multicolumn{4}{|c|}{ G3: score of preferred day off assignments } \\
\hline & & $\begin{array}{l}\text { Total } \\
\text { shifts }\end{array}$ & $S_{i}^{-}$ & $\begin{array}{c}S \\
\text { Target }\end{array}$ & $\begin{array}{c}\% \\
\text { Dev }^{*}\end{array}$ & $\begin{array}{c}\text { Total preferred } \\
\text { shifts }\end{array}$ & $P S_{i}^{-}$ & $\begin{array}{c}\text { PS } \\
\text { Target }\end{array}$ & $\begin{array}{c}\% \\
\text { Dev* }^{*}\end{array}$ & $\begin{array}{c}\text { Total preferred day } \\
\text { off scores }\end{array}$ & $P D_{i}^{-}$ & $\begin{array}{c}P D \\
\text { Target }\end{array}$ & $\begin{array}{c}\% \\
\text { Dev* }^{*}\end{array}$ \\
\hline 1 & 24 & 22 & 2 & 24 & 4.6 & 20 & 0 & 20 & 6.3 & 12 & 0 & 12 & 23.6 \\
\hline 2 & 20 & 24 & 0 & 24 & 4.1 & 19 & 1 & 20 & 0.9 & 9 & 3 & 12 & 7.3 \\
\hline 3 & 20 & 24 & 0 & 24 & 4.1 & 19 & 1 & 20 & 0.9 & 4 & 5 & 12 & 58.8 \\
\hline 4 & 20 & 24 & 0 & 24 & 4.1 & 17 & 3 & 20 & 9.7 & 4 & 5 & 12 & 58.8 \\
\hline 5 & 24 & 24 & 0 & 24 & 4.1 & 19 & 1 & 20 & 0.9 & 12 & 0 & 12 & 23.6 \\
\hline 6 & 23 & 24 & 0 & 24 & 4.1 & 17 & 3 & 20 & 9.7 & 10 & 4 & 12 & 3.0 \\
\hline 7 & 21 & 24 & 0 & 24 & 4.1 & 20 & 0 & 20 & 6.3 & 12 & 0 & 12 & 23.6 \\
\hline 8 & 22 & 24 & 0 & 24 & 4.1 & 19 & 1 & 20 & 0.9 & 10 & 2 & 12 & 3.0 \\
\hline 9 & 24 & 24 & 0 & 24 & 4.1 & 20 & 0 & 20 & 6.3 & 6 & 9 & 12 & 38.2 \\
\hline 10 & 20 & 23 & 1 & 24 & 0.3 & 20 & 0 & 20 & 6.3 & 7 & 2 & 12 & 27.9 \\
\hline 11 & 20 & 22 & 2 & 24 & 4.6 & 20 & 0 & 20 & 6.3 & 11 & 1 & 12 & 13.3 \\
\hline 12 & 24 & 22 & 2 & 24 & 4.6 & 15 & 5 & 20 & 20.3 & 12 & 0 & 12 & 23.6 \\
\hline 13 & 20 & 22 & 2 & 24 & 4.6 & 16 & 4 & 20 & 15.0 & 12 & 0 & 12 & 23.6 \\
\hline 14 & 20 & 23 & 1 & 24 & 0.3 & 19 & 1 & 20 & 0.9 & 11 & 1 & 12 & 13.3 \\
\hline 15 & 24 & 22 & 2 & 24 & 4.6 & 20 & 0 & 20 & 6.3 & 12 & 1 & 12 & 23.6 \\
\hline 16 & 24 & 22 & 2 & 24 & 4.6 & 20 & 0 & 20 & 6.3 & 10 & 1 & 12 & 3.0 \\
\hline 17 & 24 & 22 & 2 & 24 & 4.6 & 20 & 0 & 20 & 6.3 & 11 & 0 & 12 & 13.3 \\
\hline Average & & & & & 3.8 & & & & 6.4 & & & & 22.5 \\
\hline
\end{tabular}

$* \%$ Dev $=$ percent deviation from the average value.

TABLE 7: Comparison among the manual and optimal nurse schedules.

\begin{tabular}{lcccrrr}
\hline & \multicolumn{2}{c}{$\begin{array}{c}\text { G1: no. of working } \\
\text { shifts balancing }\end{array}$} & \multicolumn{2}{c}{$\begin{array}{c}\text { G2: no. of preferred } \\
\text { shift assignments }\end{array}$} & \multicolumn{2}{c}{$\begin{array}{c}\text { G3: score of preferred } \\
\text { day off assignments }\end{array}$} \\
& Average & STD & Average & STD & Average & STD \\
\hline Manual & 22 & 1.84 & - & - & - \\
Normal capacity & 23.06 & 0.64 & 19.17 & 1.24 & 11.32 \\
Extended capacity & 23.8 & 0.4 & 19.75 & 0.89 & 11.15 \\
Higher demand for experienced nurses & 23.04 & 0.94 & 18.82 & 1.60 & 9.70 \\
\hline
\end{tabular}

STD $=$ standard deviation.

patients. The number of experienced nurses required during these peak-patient-demand shifts increases from 3 to 5 . The model is solved again, and the results are summarized in Table 6. Under this scenario, experienced nurses are subject to more workloads. For most of them, their number of working shifts reaches the maximum allowable level. The ability to maximize nurse preference is now restricted by the requirement for more experienced nurses during peak time. When compared to all the previous scenarios, the average values of percent deviation for all the goals are higher. This is because experienced nurses can no longer take leaves on Monday and Tuesday, and their day off preference cannot be completely satisfied. However, under this scenario, the proposed model still offers a better working-shift balance, compared to the manual scheduling results.

The comparison of performance measures among the manual schedule and optimal schedules is made. The average and standard deviation associated with each goal's performance measure are shown in Table 7. The optimal schedules can be benchmarked against the manual schedule on the aspect of working shift balance only. Before this study, the scheduling of working shifts did not incorporate the preferred shifts and day off information.
The proposed model outperforms the actual schedule in terms of solution quality and execution time. For manual scheduling, it usually required about 1 week to prepare a 1month schedule. Regarding the working shifts balancing objective, even for the higher-demand scenario, the optimal schedule yields a significantly lower standard deviation suggesting that the model provides a more balanced workload assignment than the manual scheduling. This optimal schedule is also achieved in light of the preferred shift and day off consideration.

\section{Conclusions}

The nurse scheduling tool is essential in creating an efficient nurse shift-rotation schedule. Manual scheduling is timeconsuming and prone to overlooking some of the desirable scheduling characteristics. This study develops a nurse scheduling tool that can proportionally assign shifts to nurses while maximizing their individual preferences on shift and day off. The scheduling outcomes are expected to improve the nurse's perception of fairness and job satisfaction, which positively influences nurse retention. This study contributes to the practicality aspect of the existing NSP literature by illustrating how to formulate and solve a 
job-satisfaction enhanced model based on an actual case study. The collection of operational and preference data is obtained via field and questionnaire surveys with the nurses at the operating room department in a private hospital in Pathum Thani, Thailand. The proposed model employs the goal programming technique, enabling the consideration of multiple goals: (1) minimizing the unbalanced workload, (2) minimizing the unbalanced preferred shift, and (3) minimizing the unbalanced preferred day off among the nurses. The three problem scenarios with slightly different problem sizes are solved to optimality to show its performance based on the solution quality and computational time. The optimal solutions obtained from the proposed approach show a significant improvement compared to the manually made schedule on the aspect of workload balance. The use of a scheduling optimization approach also allows any change in the operational and preference parameters to be made and solving the new optimal schedules easily. On the job satisfaction factor aspect, this study strengthens the existing NSP literature by considering both workforce- and individual-level preferences. The workload fairness is regarded as the workforce-level desirable characteristics. The case study research that simultaneously considers both preference levels is limited.

The proposed goal programming nurse scheduling model should be able to assist the head nurse in assigning a more balanced workload while maximizing nurses' shift and day off preferences. The proposed scheduling approach can be modified in many ways when applying to other NSP. The shift balancing objective can be modified to consider other scheduling characteristics such as the heterogeneity of tasks, nurse income, and the interrelation between nurses. The hard constraints in the proposed model, such as the number of nurses in each shift and the minimum and the maximum numbers of working shifts per month, can be formulated as soft constraints or goal equations to improve the scheduling flexibility and the ability to fulfill management policy. The proposed model is based on Microsoft Excel and can be modified and implemented without additional software cost and programming difficulty.

Future studies should engage more in the practical application of the NSP approach. More NSP studies that investigate and incorporate the job satisfaction factors of nurses and uncertainties based on the actual case study are needed. According to the existing NSP literature, the differences in job satisfaction factors from case to case can be observed. The operational uncertainties such as patient demand and nurse availability experienced in each case should be addressed with the proper model formulation and solving approaches. The lack of uncertainty consideration is one of the limitations of the current study. The fairness in workload and preferred shift and day off assignments in this study is short-term, over just 28 days. In our future study, the scheduling approach should be able to account for the historical scheduling outcomes to generate the solution with long-term fairness.

\section{Data Availability}

Data are available upon request to the corresponding author.

\section{Conflicts of Interest}

The authors declare that there are no conflicts of interest regarding the publication of this paper.

\section{Acknowledgments}

The authors would like to express their gratitude to the head nurse and the operating-room nurses at the hospital case study for their supportive cooperation. The authors also would like to thank the research assistants for their data collection efforts. This study was supported by Thammasat University Research Fund, Contract No. TUFT 052/2563.

\section{References}

[1] M. Marć, A. Bartosiewicz, J. Burzyńska, Z. Chmiel, and P. Januszewicz, "A nursing shortage-a prospect of global and local policies," International Nursing Review, vol. 66, no. 1, pp. 9-16, 2019.

[2] J. Bridges, P. Griffiths, E. Oliver, and R. M. Pickering, "Hospital nurse staffing and staff-patient interactions: an observational study," BMJ Quality \& Safety, vol. 28, no. 9, pp. 706-713, 2019.

[3] L.-F. Liu, S. Lee, P.-F. Chia, S.-C. Chi, and Y.-C. Yin, "Exploring the association between nurse workload and nursesensitive patient safety outcome indicators," Journal of Nursing Research, vol. 20, no. 4, pp. 300-309, 2012.

[4] J. A. Baker, K. Canvin, and K. Berzins, "The relationship between workforce characteristics and perception of quality of care in mental health: a qualitative study," International Journal of Nursing Studies, vol. 100, Article ID 103412, 2019.

[5] S. Uekata, C. Kato, Y. Nagaura, H. Eto, and H. Kondo, “The impact of rotating work schedules, chronotype, and restless legs syndrome/Willis-Ekbom disease on sleep quality among female hospital nurses and midwives: a cross-sectional survey," International Journal of Nursing Studies, vol. 95, pp. 103-112, 2019.

[6] A. Aamir, A. B. A. Hamid, M. Haider, and C. S. Akhtar, "Work-life balance, job satisfaction and nurses retention: moderating role of work volition," International Journal of Business Excellence, vol. 10, no. 4, p. 488, 2016.

[7] H. Baek, K. Han, and E. Ryu, "Authentic leadership, job satisfaction and organizational commitment: the moderating effect of nurse tenure," Journal of Nursing Management, vol. 27, no. 8, pp. 1655-1663, 2019.

[8] S. D. Al Sabei, L. J. Labrague, A. Miner Ross et al., "Nursing work environment, turnover intention, job burnout, and quality of care: the moderating role of job satisfaction," Journal of Nursing Scholarship, vol. 52, no. 1, pp. 95-104, 2020.

[9] E. Halcomb and S. Bird, "Job satisfaction and career intention of Australian general practice nurses: a cross-sectional survey," Journal of Nursing Scholarship, vol. 52, no. 3, pp. 270-280, 2020.

[10] D. Dede and J. McCreary, "Home health nursing job satisfaction and retention," Nursing Clinics of North America, vol. 55, no. 1, pp. 121-132, 2020.

[11] U. Martin and S. P. Schinke, "Organizational and individual factors influencing job satisfaction and burnout of mental health workers," Social Work in Health Care, vol. 28, no. 2, pp. 51-62, 1998.

[12] F. DeKeyser Ganz and O. Toren, "Israeli nurse practice environment characteristics, retention, and job satisfaction," 
Israel Journal of Health Policy Research, vol. 3, no. 1, pp. 1-8, 2014.

[13] R. AbuAlRub, F. El-Jardali, D. Jamal, and N. Abu Al-Rub, "Exploring the relationship between work environment, job satisfaction, and intent to stay of Jordanian nurses in underserved areas," Applied Nursing Research, vol. 31, pp. 19-23, 2016.

[14] X. Li, Y. Zhang, D. Yan, F. Wen, and Y. Zhang, "Nurses' intention to stay: the impact of perceived organizational support, job control and job satisfaction," Journal of Advanced Nursing, vol. 76, no. 5, pp. 1141-1150, 2020.

[15] M. Giles, V. Parker, R. Mitchell, and J. Conway, "How do nurse consultant job characteristics impact on job satisfaction? An Australian quantitative study," BMC Nursing, vol. 16, no. 1, pp. 1-10, 2017.

[16] C. B. Mahoney, J. Lea, P. L. Schumann, and I. A. Jillson, "Turnover, burnout, and job satisfaction of certified registered nurse anesthetists in the United States: role of job characteristics and personality," AANA Journal, vol. 88, no. 1, pp. 39-48, 2020.

[17] C. Koning, "Does self-scheduling increase nurses' job satisfaction? An integrative literature review," Nursing Management, vol. 21, no. 6, pp. 24-28, 2014.

[18] T. Cao, X. Huang, L. Wang et al., "Effects of organisational justice, work engagement and nurses' perception of care quality on turnover intention among newly licensed registered nurses: a structural equation modelling approach," Journal of Clinical Nursing, vol. 29, pp. 1-12, 2020.

[19] I. Rizany, R. T. S. Hariyati, E. Afifah, and Rusdiyansyah, "The impact of nurse scheduling management on nurses' job satisfaction in army hospital: a cross-sectional research," SAGE Open, vol. 9, no. 2, 2019.

[20] A. A. El Adoly, M. Gheith, and M. Nashat Fors, "A new formulation and solution for the nurse scheduling problem: a case study in Egypt," Alexandria Engineering Journal, vol. 57, no. 4, pp. 2289-2298, 2018.

[21] S.-P. Wang, Y.-K. Hsieh, Z.-Y. Zhuang, and N.-C. Ou, "Solving an outpatient nurse scheduling problem by binary goal programming," Journal of Industrial and Production Engineering, vol. 31, no. 1, pp. 41-50, 2014.

[22] K. Thongsanit, K. Kantangkul, and T. Nithimethirot, "Nurse's shift balancing in nurse scheduling problem," Silpakorn University Science and Technology, vol. 10, no. 1, pp. 43-48, 2016.

[23] E. Çetin and A. Sarucan, "Nurse scheduling using binary fuzzy goal programming," in Proceedings of the 6th International Conference on Modeling, Simulation, and Applied Optimization (ICMSAO), Istanbul, Turkey, May 2015.

[24] C.-C. Lin, J.-R. Kang, W.-Y. Liu, and D.-J. Deng, "Modelling a nurse shift schedule with multiple preference ranks for shifts and days-off," Mathematical Problems in Engineering, vol. 2014, Article ID 937842, 10 pages, 2014.

[25] Y.-C. Huang, Y.-H. Hsieh, and F.-y. Hsia, "A study on nurse day-off scheduling under the consideration of binary preference," Journal of Industrial and Production Engineering, vol. 33, no. 6, pp. 363-372, 2016.

[26] M. Widyastiti, A. Aman, and T. Bakhtiar, "Nurses scheduling by considering the qualification using integer linear programming," TELKOMNIKA (Telecommunication Computing Electronics and Control), vol. 14, no. 3, p. 933, 2016.

[27] M. Bagheri, A. Gholinejad Devin, and A. Izanloo, "An application of stochastic programming method for nurse scheduling problem in real word hospital," Computers \& Industrial Engineering, vol. 96, pp. 192-200, 2016.
[28] G. J. Lim, A. Mobasher, and M. J. Côté, "Multi-objective nurse scheduling models with patient workload and nurse preferences," Management, vol. 2, no. 5, pp. 149-160, 2012.

[29] W. Agyei, W. Obeng-denteh, and E. A. Andaam, "Modeling nurse scheduling problem using 0-1 goal programming A case study of tafo government hospital Kumasi-Ghana," International Journal of Scientific \& Technology Research, vol. 4, no. 3, pp. 5-10, 2015.

[30] N. Al-Hinai, N. Al-Yazidy, A. Al-Hooti, and E. Al-Shereiqi, "A goal programming model for nurse scheduling at emergency department," in Proceedings of the International Conference on Industrial Engineering and Operations Management, pp. 99-103, Bandung, Indonesia, March 2018.

[31] A. Dumrongsiri and P. Chongphaisal, "Nurse scheduling in a hospital emergency department: a case study at a Thai University hospital," Songklanakarin Journal of Science and Technology, vol. 40, no. 1, pp. 187-196, 2018.

[32] M. Mohammadian, M. Babaei, M. A. Jarrahi, and E. Anjomrouz, "Scheduling nurse shifts using goal programming based on nurse preferences: a case study in an emergency department," International Journal of Engineering, vol. 32, no. 7, 2019.

[33] V. E. Sundari and S. Mardiyati, "Solving cyclical nurse scheduling problem using preemptive goal programming," AIP Conference Proceedings, vol. 1862, Article ID 030132, 2017.

[34] D. Santos, P. Fernandes, H. L. Cardoso, and E. Oliveira, "A weighted constraint optimization approach to the nurse scheduling problem," in Proceedings of the 2015 IEEE 18th International Conference on Computational Science and Engineering, pp. 233-239, Porto, Portugal, October 2015.

[35] F. Mischek and N. Musliu, "Integer programming model extensions for a multi-stage nurse rostering problem," Annals of Operations Research, vol. 275, 2017.

[36] E. Rahimian, K. Akartunalı, and J. Levine, "A hybrid integer and constraint programming approach to solve nurse rostering problems," Computers \& Operations Research, vol. 82, pp. 83-94, 2017.

[37] M. Chiaramonte and D. Caswell, "Rerostering of nurses with intelligent agents and iterated local search," IIE Transactions on Healthcare Systems Engineering, vol. 6, no. 4, pp. 213-222, 2016.

[38] X. Zhong, J. Zhang, and X. Zhang, "A two-stage heuristic algorithm for the nurse scheduling problem with fairness objective on weekend workload under different shift designs," IISE Transactions on Healthcare Systems Engineering, vol. 7, no. 4, pp. 224-235, 2017.

[39] K. L. Maass, B. Liu, M. S. Daskin et al., "Incorporating nurse absenteeism into staffing with demand uncertainty," Health Care Management Science, vol. 20, no. 1, pp. 141-155, 2017.

[40] K. Leksakul and S. Phetsawat, "Nurse scheduling using genetic algorithm," Mathematical Problems in Engineering, vol. 2014, Article ID 246543, 16 pages, 2014.

[41] S. M. Sajadi, S. Ghasemi, and H. Vahdani, "Simulation optimisation for nurse scheduling in a hospital emergency department (case study: shahid Beheshti Hospital)," International Journal of Industrial and Systems Engineering, vol. 23, no. 4, p. 405, 2016.

[42] Q. Liu, B. Niu, J. Wang, H. Wang, and L. Li, "Nurse scheduling problem based on hydrologic cycle optimization," in Proceedings of the 2019 IEEE Congress on Evolutionary Computation (CEC), pp. 1398-1405, Wellington, New Zealand, June 2019.

[43] F. Guessoum, S. Haddadi, and E. Gattal, "Simple, yet fast and effective two-phase method for nurse rostering," American 
Journal of Mathematical and Management Sciences, vol. 39, pp. 1-19, 2020.

[44] S. Petrovic, "“You have to get wet to learn how to swim" applied to bridging the gap between research into personnel scheduling and its implementation in practice," Annals of Operations Research, vol. 275, no. 1, pp. 161-179, 2019.

[45] P. Rerkjirattikal, T. Wanwarn, S. Starita, and V. Huynh, "Heuristics for noise-safe job-rotation problems considering learning-forgetting and boredom-induced job dissatisfaction effects," Environmental Engineering and Management, vol. 19, no. 8, pp. 1325-1337, 2020. 